\title{
Heat and Mass Transfer in Reduction Zone of Sponge Iron Reactor
}

\author{
Bayu Alamsari, ${ }^{1}$ Shuichi Torii, ${ }^{1}$ Azis Trianto, ${ }^{2}$ and Yazid Bindar ${ }^{2}$ \\ ${ }^{1}$ Department of Mechanical System Engineering, Kumamoto University, Kumamoto 860-8555, Japan \\ ${ }^{2}$ Department of Chemical Engineering, Bandung Institute of Technology, Bandung 40132, Indonesia
}

Correspondence should be addressed to Azis Trianto, asia1964@yahoo.co.jp

Received 13 March 2011; Accepted 14 May 2011

Academic Editor: S.-H. Chuang

Copyright () 2011 Bayu Alamsari et al. This is an open access article distributed under the Creative Commons Attribution License, which permits unrestricted use, distribution, and reproduction in any medium, provided the original work is properly cited.

\begin{abstract}
Numerical prediction is performed on reduction zone of iron ore reactor which is a part of counter current gas-solid reactor for producing sponge iron. The aim of the present study is to investigate the effect of reduction gas composition and temperature on quality and capacity of sponge iron products through mathematical modeling arrangement and simulation. Simultaneous mass and energy balances along the reactor lead to a set of ordinary differential equation which includes kinetic equations. Kinetic equations of reduction of hematite to iron metal, methane reforming, and water gas shift reaction are taken into account in the model. Hydrogen and carbon monoxide are used as reduction gas. The equations were solved by finite element method. Prediction shows an increase in $\mathrm{H}_{2}$ composition while an attenuation of $\mathrm{CO}$ produces higher metallization degree. Metallization degree is also increased with an increase in gas inlet temperature. It is found that reduction gas temperature over $973^{\circ} \mathrm{C}(1246 \mathrm{~K})$ is not recommended because the formation of sticky iron will be initiated.
\end{abstract}

\section{Introduction}

Sponge iron product quality in direct Reduced iron (DRI) plant can be increased by rising reduction gas temperature and composition of reactant in reduction gas. The rising of temperature will accelerate reaction flow rate which in turn can raise reaction conversion as shown by Zhang and Ostrovski [1]. However, the temperature rising can also bring disadvantage due to the formation of total carbon on the product. The increasing of reactant composition which is consisted of $\mathrm{H}_{2}$ and $\mathrm{CO}$ in reduction gas will also increase product quality as reported by many researchers (e.g., [2$4]$ ). The optimum composition of reduction gas must be determined to obtain the highest quality.

The investigation of temperature and composition of reduction gas is carried out by analyzing the performance of sponge iron reactor which in turn can predict the profitable optimum condition of reactor. However, since the reactor analysis is difficult to be executed directly in the field plant, it will need a simulator as support instrument. This simulator can be designed by arrangement of heat and mass transfer equation inside the reactor to reproduce reactor data from the field. By solving heat and mass transfer equations, the effect of reduction gas on the performance of reactor is studied.
Some iron ore reactor models are proposed in a few literatures. Iron ore reactor model proposed by Aguilar et al. [5] is referred for fixed bed reactor. The model is derived based on unsteady state condition. Parisi and Laborde [6] proposed a model for moving bed counter current reactor. The model is limited on reduction zone of iron ore reactor, and only reduction reactions are considered in the model, in which plug flow is used as an approach for the model.

Another related model is formulated on direct reduction shaft furnace for producing sponge iron from iron ore as proposed by Takenaka et al. [7]. In their model, reduction rate equations are derived from the three-interface model which involves both mass and heat balances. Srinivasan [8] develops a model for reduction iron oxides by carbon. This model in which only the global direct reduction reactions are taken into account and methane reforming and water gas shift reaction are ignored, is formulated on a circulating fluidized bed reactor.

The kinetics of direct reduction reaction plays an important role in sponge iron reduction zone mathematical model. Unreacted core model proposed by Levenspiel [9] is widely used for kinetics model of iron reduction in which the reaction occurs first at the outer skin of the particle. The zone of reaction then moves into the solid and may leave behind 
completely converted material and inert solid. Thus, at any time, there exists an unreacted core of material which shrinks in size during reaction.

Mondal et al. [10] propose the another kinetics model for iron reduction. Here, the kinetic constants are derived based on Arrhenius equation and Cementite formation reaction was also taken into account in their model. Note that this model is only applicable for iron reduction using $\mathrm{CO}$ as reducer. Iguchi and Yokomoto [11] also suggest kinetics model based on Arrhenius equation but cementite formation was ignored.

In the present study, heat and mass transfer in sponge iron reactor reduction zone are studied. Here, the model can be used to explore the performance of sponge iron reactor. In particular, the effect of reduction gas composition and temperature on quality and capacity of sponge iron products is precisely disclosed, because kinetics equation of reduction of hematite to iron metal, methane reforming, and water gas shift reaction are taken into account in the model.

\section{Reactor Modeling}

Iron ore reactor is a moving bed reactor to produce sponge iron product from iron ore. Gas and solid phases are passed in counter current. In general, sponge ore reactor is divided by 3 zones, which are referred to as reduction, isobaric, and cooling zones. The simple scheme of iron ore reactor is shown in Figure 1. In the reduction zone, there are some reactions occurring between reduction gas and iron ore pellets. These reactions which are called reduction reaction will extract iron metal from the ore to create sponge iron product. These reactions occur on the surface of iron ore pellet. In general, hydrogen and carbon monoxide are used as reducer and the corresponding reduction reactions are shown as follows:

$$
\begin{aligned}
3 \mathrm{Fe}_{2} \mathrm{O}_{3}+\mathrm{CO}\left(\mathrm{H}_{2}\right) & \Longleftrightarrow 2 \mathrm{Fe}_{3} \mathrm{O}_{4}+\mathrm{CO}_{2}\left(\mathrm{H}_{2} \mathrm{O}\right) \\
\mathrm{Fe}_{3} \mathrm{O}_{4}+\mathrm{CO}\left(\mathrm{H}_{2}\right) & \Longleftrightarrow 3 \mathrm{FeO}+\mathrm{CO}_{2}\left(\mathrm{H}_{2} \mathrm{O}\right) \\
\mathrm{FeO}+\mathrm{CO}\left(\mathrm{H}_{2}\right) & \Longleftrightarrow \mathrm{Fe}+\mathrm{CO}_{2}\left(\mathrm{H}_{2} \mathrm{O}\right) .
\end{aligned}
$$

Methane reforming and water gas shift reactions also occur in the gas phase based on the composition of reduction gas and temperature through reaction as follows:

$$
\begin{aligned}
& \mathrm{CH}_{4}+\mathrm{H}_{2} \mathrm{O} \Longleftrightarrow \mathrm{CO}_{2}+\mathrm{H}_{2} \\
& \mathrm{CO}_{2}+\mathrm{H}_{2} \Longleftrightarrow \mathrm{CO}+\mathrm{H}_{2} \mathrm{O} .
\end{aligned}
$$

Mathematical model of reduction zone in iron ore reactor is arranged on the gas and solid phases. Heat and mass transfer equations are formulated to perform the temperature and concentration of gas and solid phases, respectively. The modeling is also carried out by employing kinetics model. Note that iron reduction, methane reforming, and water gas shift reactions are taken into account in the model.

The mass and energy equations are formulated by assuming (i) steady-state operating conditions, (ii) no heat loss over the wall of reactor reduction zone, (iii) the iron ore pellet consumption is governed by the unreacted shrinking core model, (iv) the enthalpy is calculated based on temperature changes, and ( $\mathrm{v}$ ) the plug flow is used to approach a model for gas and solid phases. By considering the above assumptions, heat and mass balance equations can be stated as follows:

$$
\begin{aligned}
& \bar{u}_{\text {gas }} \frac{d C_{\mathrm{CH}_{4}}}{d z}=r_{\text {methanation }}\left(\mathrm{CH}_{4}, \mathrm{H}_{2}, T_{\text {gas }}\right) \text {, } \\
& \bar{u}_{\text {gas }} \frac{d C_{\mathrm{H}_{2}}}{d z}=r_{\mathrm{WGSR}}\left(\mathrm{CO}, T_{\mathrm{gas}}\right) \\
& +r_{\text {methanation }}\left(\mathrm{CH}_{4}, \mathrm{H}_{2}, T_{\text {gas }}\right) \\
& -n_{p} \cdot r_{\mathrm{H}_{2} \text {-reduction }}\left(\mathrm{H}_{2}, T_{\text {solid }}\right) \text {, } \\
& \bar{u}_{\text {gas }} \frac{d C_{\mathrm{CO}}}{d z}=r_{\mathrm{WGSR}}\left(\mathrm{CO}, T_{\mathrm{gas}}\right) \\
& +r_{\text {methanation }}\left(\mathrm{CH}_{4}, \mathrm{H}_{2}, T_{\text {gas }}\right) \\
& -n_{p} \cdot r_{\mathrm{CO}-\text { reduction }}\left(\mathrm{CO}, \mathrm{T}_{\text {solid }}\right) \text {, } \\
& \bar{u}_{\text {solid }} \frac{d C_{\mathrm{Fe}_{2} \mathrm{O}_{3}}}{d z}=n_{p} \cdot r_{\mathrm{Fe}_{2} \mathrm{O}_{3}}\left(\mathrm{CO}, \mathrm{H}_{2}, T_{\text {solid }}\right) \text {, } \\
& \bar{u}_{\text {solid }} \frac{d C_{\mathrm{Fe}_{3} \mathrm{O}_{4}}}{d z}=n_{p} \cdot r_{\mathrm{Fe}_{3} \mathrm{O}_{4}}\left(\mathrm{CO}, \mathrm{H}_{2}, T_{\text {solid }}\right) \text {, } \\
& \bar{u}_{\text {solid }} \frac{d C_{\mathrm{FeO}}}{d z}=n_{p} \cdot r_{\mathrm{FeO}}\left(\mathrm{CO}, \mathrm{H}_{2}, T_{\text {solid }}\right) \text {, } \\
& \bar{u}_{\text {solid }} \frac{d C_{\mathrm{Fe}}}{d z}=n_{p} \cdot r_{\mathrm{Fe}}\left(\mathrm{CO}, \mathrm{H}_{2}, T_{\text {solid }}\right), \\
& \frac{d T_{\mathrm{gas}}}{d z}=\frac{A_{s p} \cdot h\left(T_{\mathrm{solid}}-T_{\mathrm{gas}}\right)}{M_{\mathrm{gas}} \cdot C p_{\mathrm{gas}}}+\frac{R f_{\mathrm{gas}} \sum\left[H_{i} r_{i}\right]}{M_{\mathrm{gas}} \cdot C p_{\mathrm{gas}}}, \\
& \frac{d T_{\text {solid }}}{d z}=\frac{A_{s p} \cdot h \cdot\left(T_{\text {solid }}-T_{\text {gas }}\right)}{M_{\text {solid }} \cdot C p_{\text {solid }}}-\frac{\sum\left[H_{i} r_{i}\right]}{M_{\text {solid }} \cdot C p_{\text {solid }}} .
\end{aligned}
$$

Equations (6)-(8) are mass balance equations for gas phase, while (9)-(12) are for solid phase. Heat balance equations for gas and solid phase are expressed by (13) and (14), respectively. Notation $A_{s p}$ is pellets surface area per unit reactor volume, $h$ is convection heat transfer coefficient, and $M$ is molar flow rate.

Heat capacities $(C p)$ of gas and solid phases in (13) and (14) are calculated based on the temperature changes in each phase. On the gas phase, heat capacity value is calculated based on the mixing of heat capacity of $\mathrm{CO}$ and $\mathrm{H}_{2}$. The other components such as $\mathrm{H}_{2} \mathrm{O}, \mathrm{CH}_{4}, \mathrm{CO}_{2}$, and $\mathrm{N}_{2}$ are omitted because they have small fraction compared to $\mathrm{CO}$ and $\mathrm{H}_{2}$. The heat capacity of gas phase is evaluated as follows:

$$
C p_{\text {gas }}=\left(\frac{C_{\mathrm{CO}}}{C_{\mathrm{CO}}+C_{\mathrm{H}_{2}}} C p_{\mathrm{CO}}\right)+\left(\frac{C_{\mathrm{H}_{2}}}{C_{\mathrm{CO}}+C_{\mathrm{H}_{2}}} C p_{\mathrm{H}_{2}}\right)
$$




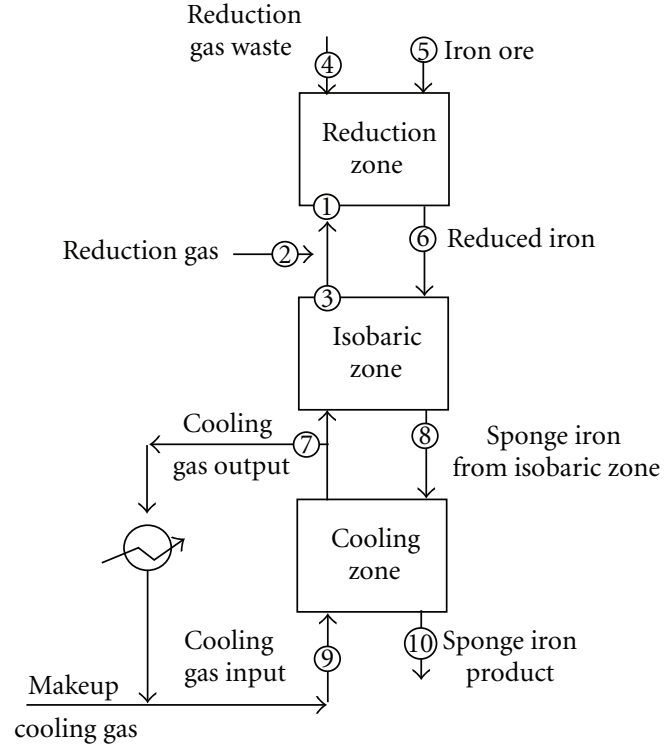

FIGURE 1: Scheme of sponge iron reactor.

where

$$
C p\left(\mathrm{CO} \text { or } \mathrm{H}_{2}\right)=a_{1} T_{\mathrm{gas}}-a_{2} T_{\mathrm{gas}}^{2}+a_{3} T_{\mathrm{gas}}^{3}-a_{4} T_{\mathrm{gas}}^{4}+a_{5} T_{\mathrm{gas}}^{5} .
$$

Here, constant values of $a_{1}, a_{2}, a_{3}, a_{4}$, and $a_{5}$ for CO and $\mathrm{H}_{2}$ are defined by Reklaitis [12]. Heat capacity of solid phase is calculated based on heat capacity of Fe. Heat capacity parameter of Fe as obtained from Green and Perry [13] is shown as follows:

$$
C p_{(\mathrm{Fe})}=0.0029 T_{\text {solid }}-5 E^{-6} T_{\text {solid }}^{2}+3 E^{-9} T_{\text {solid }}^{3} .
$$

Standard reaction enthalpy $\left(H_{i}\right)$ and kinetic equation $\left(r_{i}\right)$ in (13) and (14) are calculated based on reactions in each phase. Sigma notation $\left(\sum H_{i} r_{i}\right)$ in (13) is calculated through methanation and water gas shift reactions, while $\left(\sum H_{i} r_{i}\right)$ in (14) is calculated by reduction reactions of $\mathrm{CO}$ and $\mathrm{H}_{2}$. The formulation of sigma notation for (13) is described as follows:

$$
\begin{aligned}
\left(\sum H_{i} r_{i}\right)= & {\left[\left(H_{R(298)-\text { methanation }}+\int_{T_{\text {gas }}}^{T_{o}} C p_{R} d T\right) r_{\text {methanation }}\right] } \\
& +\left[\left(H_{R(298)-W G S R}+\int_{T_{\text {gas }}}^{T_{o}} C p_{R} d T\right) r_{\text {WGSR }}\right],
\end{aligned}
$$

while formulation of sigma notation for (14) is as follows:

$$
\begin{aligned}
& \left(\sum H_{i} r_{i}\right) \\
& =\left[\left(H_{R(298) \text { _CO-reduction }}+\int_{T_{\text {solid }}}^{T_{o}} C p_{R} d T\right) r_{\text {CO-reduction }}\right] \\
& \quad+\left[\left(H_{R(298) \_\mathrm{H}_{2} \text {-reduction }}+\int_{T_{\text {solid }}}^{T_{o}} C p_{R} d T\right) r_{\mathrm{H}_{2} \text {-reduction }}\right] .
\end{aligned}
$$

The values of standard reaction enthalpy at $298 \mathrm{~K}\left(H_{R(298)}\right)$ for each reaction are obtained from Chemical Sciences [12]. Reaction heat capacity $\left(C p_{R}\right)$ is also calculated for each reaction by using

$$
C p_{R}=\sum_{i} b_{i} C p_{i \text {-reactant }}-\sum_{j} b_{j} C p_{j \text {-product }},
$$

where $i$ and $j$ refer to reactant and product number, respectively. Notation $b$ is stoichiometric coefficient for each reactant and product.

Heat transfer coefficient, $h$, is determined by using the correlation proposed by Furnas [14]. He investigates heat transfer value from a stream of air to a bed of iron pellets covered with a thin coating of iron oxides. The temperature experiments are set up to $1023 \mathrm{~K}$. The equation proposed by Furnas [14] is as follows:

$$
h=6.91 \times 10^{-3} \times G_{f}^{0.75} \times T \times G^{-1.56} \times 5.67826 .
$$

Notation $r$ in (6)-(14) is referred to as kinetic expression of every reaction which occurs in reduction zone. There are three kinetic equations involved in the model, namely, a kinetic equation of methanation reaction, a kinetic equation of water gas shift reaction, and a kinetic equation of reduction reaction. Kinetic expression of methanation reaction $\left(r_{\text {methanation }}\right)$ is adopted from Munster and Grabke [15] given by

$$
r_{\text {methanation }}=f_{\text {methanation }} k_{o} a_{0} \exp \left[\frac{-E_{A}^{+}}{R T}\right]\left(\frac{p_{\mathrm{CH}_{4}}}{\sqrt{p_{\mathrm{H}_{2}}}}\right) .
$$

Here, the values of activation energy $\left(E_{A}\right)$ and preexponential constant $\left(k_{o}\right)$ are the same as those adopted in the literature [15]. Constant, $a_{0}$, is expressed as $\mathrm{pH}_{2} \mathrm{O} / \mathrm{pH}_{2}$. Note that correction factor $f_{\text {methanation }}$ proposed here is added so as to correct the value of preexponential constant.

Many researchers propose kinetic equations for water gas shift reaction. The validity of kinetic model is to get results which have a good agreement with reference data. Some kinetics models are valid for low-temperature reaction while some others are not. Bustamante et al. [16] carried out on the temperature range of $1148-1198 \mathrm{~K}$ whose condition is similar to that of the present study. Their kinetic model is shown as follows:

$$
r_{\mathrm{WGSR}}=f_{\mathrm{WGSR}} \cdot k_{o} \cdot \exp \left[\frac{-E_{A}^{+}}{R T}\right]\left(C_{\mathrm{H}_{2}}\right)^{0.33}\left(C_{\mathrm{CO}_{2}}\right) \text {. }
$$

Here, the value of $k_{o}$ is corrected by correction factor $f$.

Kinetic equations of reduction reaction in iron ore are created based on shrinking core model for spherical particles. The formulations of kinetics equation are derived based on the model proposed by Levenspiel [9]. Although many literatures propose the models such as Mondal et al. [10], Iguchi and Yokomoto [11], and Shi et al. [17]; among them, Levenspiel formulates the model in more detail by considering every step which is close with reality. Figure 2 shows the visualization of shrinking core model for iron reduction. Basically, 5 steps take place during reaction, as explained in Levenspiel [9]. 


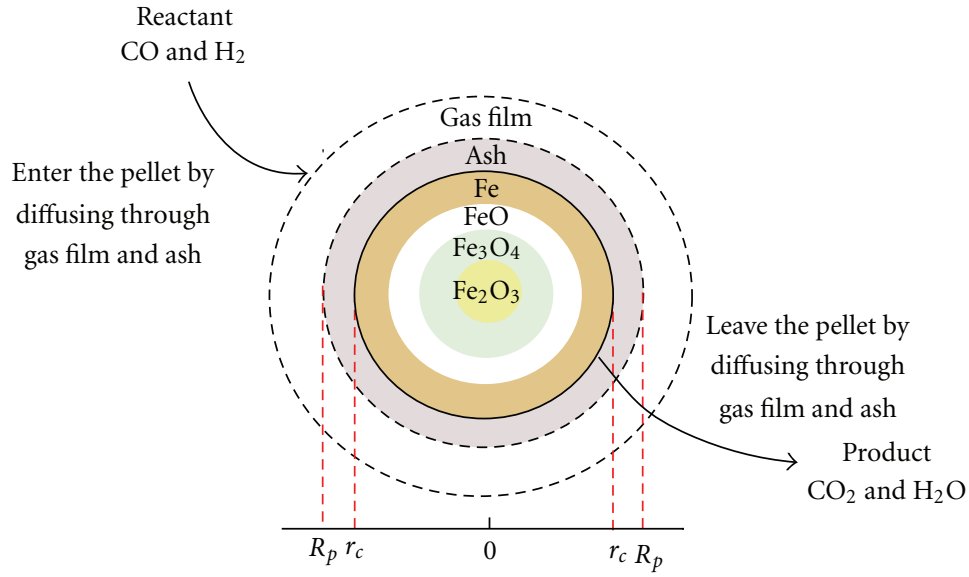

FIGURE 2: Shrinking core model.

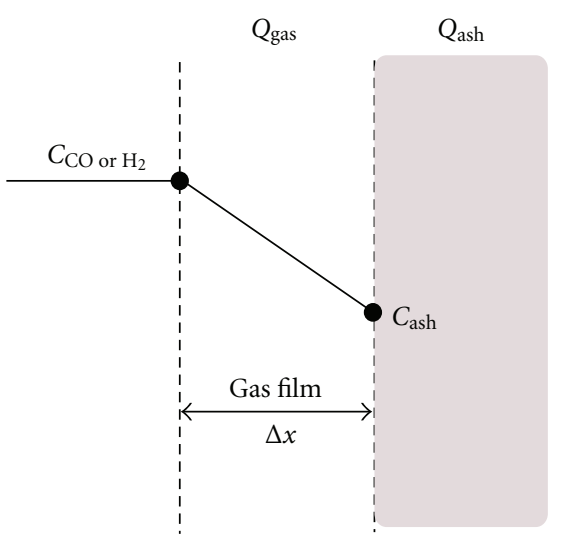

FIgUre 3: Diffusion through gas film.

(a) Diffusion of gaseous reactants $\left(\mathrm{CO}\right.$ and $\left.\mathrm{H}_{2}\right)$ through the film surrounding the particle to the surface of the solid.

(b) Diffusion of $\mathrm{CO}$ and $\mathrm{H}_{2}$ through the blanket of ash to the surface of the unreacted core of iron pellet.

(c) Reaction of $\mathrm{CO}$ and $\mathrm{H}_{2}$ with iron ore at reaction surface through

$$
\begin{gathered}
3 \mathrm{Fe}_{2} \mathrm{O}_{3}+\mathrm{CO}\left(\mathrm{H}_{2}\right) \longrightarrow 2 \mathrm{Fe}_{3} \mathrm{O}_{4}+\mathrm{CO}_{2}\left(\mathrm{H}_{2} \mathrm{O}\right) \\
\mathrm{Fe}_{3} \mathrm{O}_{4}+\mathrm{CO}\left(\mathrm{H}_{2}\right) \longrightarrow 3 \mathrm{FeO}+\mathrm{CO}_{2}\left(\mathrm{H}_{2} \mathrm{O}\right) \\
\mathrm{FeO}+\mathrm{CO}\left(\mathrm{H}_{2}\right) \longrightarrow \mathrm{Fe}+\mathrm{CO}_{2}\left(\mathrm{H}_{2} \mathrm{O}\right)
\end{gathered}
$$

(d) Diffusion of gaseous products $\left(\mathrm{CO}_{2}\right.$ and $\left.\mathrm{H}_{2} \mathrm{O}\right)$ through the ash back to gas film.

(e) Diffusion of gaseous products through the gas film back into the main body of fluid.

The kinetic equation of each step must be combined to get overall kinetic expression for each component involved in reduction reaction. Therefore, the expression of kinetic equation of each step must be defined in the same manner.
Since the rate of mass transfer (gas diffusion) on steps (a), (b), (d), and (e) can be defined as the flow of material unit surface, or

$$
Q_{\text {diffusion }}=-\frac{1}{S} \frac{d N_{\mathrm{gas}}}{d t},
$$

the reaction step (step (c)) must similarly be defined as

$$
Q_{\text {reaction }}=-\frac{1}{S} \frac{d N_{i}}{d t} .
$$

Based on those steps, we can formulate the overall kinetic equation based on 3 main equations; those are as follows.

(1) Diffusion through Gas Film Control (Steps (a) and (e)). If gas $\mathrm{CO}$ or $\mathrm{H}_{2}$ diffuses through a stagnant film onto surface of ash as shown in Figure 3, the flux of material can be defined as the flow of gas unit surface, or

$$
\begin{aligned}
Q_{\text {gas }} & =-\frac{1}{S} \frac{d N_{\mathrm{CO} \text { or } \mathrm{H}_{2}}}{d t}=D \frac{\Delta C}{\Delta r}=\frac{D}{\Delta r}\left(C_{\mathrm{CO} \text { or } \mathrm{H}_{2}}-C_{\text {ash }}\right) \\
& =k_{\text {film }}\left(C_{\mathrm{CO} \text { or } \mathrm{H}_{2}}-C_{\text {ash }}\right),
\end{aligned}
$$

where $S$ is surface area $\left(\mathrm{m}^{2}\right), N$ is mole amount of CO or $\mathrm{H}_{2}$ in mole $\left(k_{\text {film }}\right)$ is gas film kinetic constant $(\mathrm{m} / \mathrm{sec})$, $C$ is concentration $\left(\mathrm{mole} / \mathrm{m}^{3}\right)$, and $D$ is molecular diffusion coefficient $\left(\mathrm{m}^{2} / \mathrm{sec}\right)$. The same equation can also be applied for diffusion of gas product $\left(\mathrm{CO}_{2}\right.$ and $\left.\mathrm{H}_{2} \mathrm{O}\right)$.

On the ash surface, the flux diffusion can also be stated as

$$
Q_{\text {ash }}=-\frac{1}{S} \frac{d N_{\mathrm{CO} \text { or } \mathrm{H}_{2}}}{d t}=k_{\mathrm{ash}} C_{\mathrm{ash}},
$$

where $k_{\text {ash }}$ is kinetic constant on ash. Since $C_{\text {ash }}$ is difficult to be measured, this variable must be disappeared in (29) or (30). At steady state, the flow rate to the surface is equal to the reaction rate at the surface, thus

$$
\begin{gathered}
Q_{\text {gas }}=Q_{\text {ash }}, \\
k_{\text {film }}\left(C_{\mathrm{CO} \text { or H}}-C_{\text {ash }}\right)=k_{\text {ash }} C_{\text {ash }} .
\end{gathered}
$$


Therefore,

$$
C_{\text {ash }}=\frac{k_{\text {film }}}{k_{\text {film }}+k_{\text {ash }}} C_{\mathrm{CO} \text { or } \mathrm{H}_{2}} .
$$

If we insert (32) to (29) or (30), we will get

$$
\begin{aligned}
Q_{\text {gas }} & =-\frac{1}{S} \frac{d N_{\mathrm{CO} \text { or } \mathrm{H}_{2}}}{d t}=k_{\text {ash }} \frac{k_{\text {film }}}{k_{\mathrm{film}}+k_{\mathrm{ash}}} C_{\mathrm{CO} \text { or } \mathrm{H}_{2}} \\
& =k_{\mathrm{GAS}} C_{\mathrm{CO} \text { or } \mathrm{H}_{2}},
\end{aligned}
$$

where $k_{\mathrm{GAS}}$ is overall kinetic constant on gas film. Equation (33) then will be used as kinetic expression of diffusion through gas film control.

(2) Diffusion through Ash Layer Control (Steps (b) and (d)). If the flux of gas within the ash layer is expressed by Ficks law for equimolar counter diffusion, then we will have

$$
Q=-\frac{1}{S} \frac{d N_{\mathrm{CO} \text { or } \mathrm{H}_{2}}}{d t}=\wp_{e} \frac{d C_{\mathrm{CO} \text { or } \mathrm{H}_{2}}}{d r},
$$

where $\wp_{e}$ is effective diffusion coefficient of gaseous reactant in the ash layer.

If we define $S=4 \pi r^{2}$, we will get

$$
\begin{gathered}
-\frac{d N_{\mathrm{CO} \text { or } \mathrm{H}_{2}}}{d t}=4 \pi r^{2} \cdot \wp_{e} \frac{d C_{\mathrm{CO} \text { or } \mathrm{H}_{2}}}{d r}, \\
-\frac{d N_{\mathrm{CO} \text { or } \mathrm{H}_{2}}}{d t} \int_{R_{p}}^{R_{c}} \frac{d r}{r^{2}}=4 \pi \cdot \wp_{e} \int_{C_{\mathrm{CO} \text { or } \mathrm{H}_{2}} \text { at } R_{p}}^{0} d C_{\mathrm{CO} \text { or } \mathrm{H}_{2}} .
\end{gathered}
$$

Then, by integrating (34), we get

$$
-\frac{d N_{\mathrm{CO} \text { or } \mathrm{H}_{2}}}{d t}\left(\frac{1}{R_{c}}-\frac{1}{R_{p}}\right)=4 \pi \wp_{e} C_{\mathrm{CO} \text { or } \mathrm{H}_{2}} .
$$

If we multiply both sides with $1 / A_{p}$ where $A_{p}$ is pellet surface area and define $A_{p}=4 \pi R_{p}^{2}$ where $R_{p}$ is pellet radius, we get

$$
\begin{aligned}
& -\frac{1}{A_{p}} \frac{d N_{\mathrm{CO} \text { or } \mathrm{H}_{2}}}{d t}\left(\frac{1}{R_{C}}-\frac{1}{R_{p}}\right) \\
& =\frac{1}{4 \pi R_{p}^{2}} 4 \pi \wp_{e} C_{\mathrm{CO} \text { or } \mathrm{H}_{2}}=\frac{1}{R_{p}^{2}} \wp_{e} C_{\mathrm{CO} \text { or } \mathrm{H}_{2}}
\end{aligned}
$$

or

$$
\begin{aligned}
& -\frac{1}{A_{p}} \frac{d N_{\mathrm{CO} \text { or } \mathrm{H}_{2}}}{d t} \\
& =\frac{1}{R_{p}^{2}\left(\left(1 / R_{c}\right)-\left(1 / R_{p}\right)\right)} \times \wp_{e} C_{\mathrm{CO} \text { or } \mathrm{H}_{2}} .
\end{aligned}
$$

Equation (38) then will be used as kinetic expression of diffusion through ash layer control.

(3) Chemical Reaction Controls (Step (c)). There are 6 main components which involve in reduction reaction; those are hematite $\left(\mathrm{Fe}_{2} \mathrm{O}_{3}\right)$, magnetite $\left(\mathrm{Fe}_{3} \mathrm{O}_{4}\right)$, wustite $(\mathrm{FeO})$, metal iron $(\mathrm{Fe})$, carbon monoxide $(\mathrm{CO})$, and hydrogen $\left(\mathrm{H}_{2}\right)$. The reactions are assumed pseudofirst order; that is, the rate of reaction for each component is formulated as follows. (a) $\mathrm{Fe}_{2} \mathrm{O}_{3}$ :

$$
-\frac{1}{S} \frac{d N_{\mathrm{Fe}_{2} \mathrm{O}_{3}}}{d t}=-\frac{1}{4 \pi R_{c}^{2}} \frac{d N_{\mathrm{Fe}_{2} \mathrm{O}_{3}}}{d t}=k_{1} C_{\mathrm{Fe}_{2} \mathrm{O}_{3}},
$$

where $R_{c}$ is unreacted core radius in pellet.

If we multiple each side by $1 / A_{p}$ and define $A_{p}=4 \pi R_{p}^{2}$, we get

$$
-\frac{1}{A_{p}} \frac{d N_{\mathrm{Fe}_{2} \mathrm{O}_{3}}}{d t}=\frac{R_{c}^{2}}{R_{p}^{2}} k_{1} C_{\mathrm{Fe}_{2} \mathrm{O}_{3}}
$$

(b) $\mathrm{Fe}_{3} \mathrm{O}_{4}$ :

$$
-\frac{1}{A_{p}} \frac{d N_{\mathrm{Fe}_{3} \mathrm{O}_{4}}}{d t}=\frac{R_{c}^{2}}{R_{p}^{2}}\left(-X \cdot k_{1} C_{\mathrm{Fe}_{2} \mathrm{O}_{3}}+k_{2} C_{\mathrm{Fe}_{3} \mathrm{O}_{4}}\right) .
$$

(c) $\mathrm{FeO}$ :

$$
-\frac{1}{A_{p}} \frac{d N_{\mathrm{FeO}}}{d t}=\frac{R_{c}^{2}}{R_{p}^{2}}\left(-Y k_{2} C_{\mathrm{Fe}_{3} \mathrm{O}_{4}}+k_{3} C_{\mathrm{FeO}}\right) .
$$

(d) Fe:

$$
-\frac{1}{A_{p}} \frac{d N_{\mathrm{Fe}}}{d t}=\frac{R_{c}^{2}}{R_{p}^{2}}\left(-Z k_{3} C_{\mathrm{FeO}}\right)
$$

(e) CO:

$$
-\frac{b}{A_{p}} \frac{d N_{\mathrm{CO}}}{d t}=\frac{R_{c}^{2}}{R_{p}^{2}} V_{1}\left(k_{1} C_{\mathrm{Fe}_{2} \mathrm{O}_{3}}+k_{2} C_{\mathrm{Fe}_{3} \mathrm{O}_{4}}+k_{3} C_{\mathrm{FeO}}\right) .
$$

(e) $\mathrm{H}_{2}$ :

$$
-\frac{b}{A_{p}} \frac{d N_{\mathrm{H}_{2}}}{d t}=\frac{R_{c}^{2}}{R_{p}^{2}} V_{2}\left(k_{1} C_{\mathrm{Fe}_{2} \mathrm{O}_{3}}+k_{2} C_{\mathrm{Fe}_{3} \mathrm{O}_{4}}+k_{3} C_{\mathrm{FeO}}\right) .
$$

Notations $X, Y$, and $Z$ shown in (41), (42), and (43), respectively, represent the weight coefficient, while $V_{1}$ and $V_{2}$ on (44) and (45) represent equilibrium conditions.

Kinetic reaction constants $k_{1}, k_{2}$, and $k_{3}$, respectively, refer to reaction as

$$
\begin{array}{r}
3 \mathrm{Fe}_{2} \mathrm{O}_{3}+\mathrm{CO}\left(\mathrm{H}_{2}\right) \stackrel{k_{1}}{\longrightarrow} 2 \mathrm{Fe}_{3} \mathrm{O}_{4}+\mathrm{CO}_{2}\left(\mathrm{H}_{2} \mathrm{O}\right) \\
\mathrm{Fe}_{3} \mathrm{O}_{4}+\mathrm{CO}\left(\mathrm{H}_{2}\right) \stackrel{\mathrm{k}_{2}}{\longrightarrow} 3 \mathrm{FeO}+\mathrm{CO}_{2}\left(\mathrm{H}_{2} \mathrm{O}\right) \\
\mathrm{FeO}+\mathrm{CO}\left(\mathrm{H}_{2}\right) \stackrel{k_{3}}{\longrightarrow} \mathrm{Fe}+\mathrm{CO}_{2}\left(\mathrm{H}_{2} \mathrm{O}\right) .
\end{array}
$$

If we combined the 3 main equations shown above, we get the individual equation for each component involved in reduction reaction as written below.

$$
\begin{aligned}
& \text { (a) } \begin{aligned}
\mathrm{Fe}_{2} \mathrm{O}_{3}: & \frac{1}{A_{p}} \frac{d N_{\mathrm{Fe}_{2} \mathrm{O}_{3}}}{d t}= \\
& b k_{\mathrm{GAS}} C_{\mathrm{CO} \& \mathrm{H}_{2}}+\frac{b \wp_{e} C_{\mathrm{CO} \& \mathrm{H}_{2}}}{R_{p}^{2}\left(1 / R_{c}-1 / R_{p}\right)} \\
& +b \frac{R_{c}^{2}}{R_{p}^{2}}\left(k_{1\left(\mathrm{CO} \& \mathrm{H}_{2}\right)} C_{\mathrm{Fe}_{2} \mathrm{O}_{3}}\right)
\end{aligned}
\end{aligned}
$$


or

$$
\begin{aligned}
-r_{\mathrm{Fe}_{2} \mathrm{O}_{3}}= & A_{p} b k_{\mathrm{GAS}} C_{\mathrm{CO} \& \mathrm{H}_{2}}+\frac{A_{p} b \wp_{e} C_{\mathrm{CO} \& \mathrm{H}_{2}}}{R_{p}^{2}\left(1 / R_{C}-1 / R_{p}\right)} \\
& +A_{p} b \frac{R_{C}^{2}}{R_{p}^{2}}\left(k_{1\left(\mathrm{CO} \& \mathrm{H}_{2}\right)} C_{\mathrm{Fe}_{2} \mathrm{O}_{3}}\right) .
\end{aligned}
$$

(b) $\mathrm{Fe}_{3} \mathrm{O}_{4}$ :

$$
\begin{aligned}
& -r_{\mathrm{Fe}_{3} \mathrm{O}_{4}} \\
& =A_{p} b k_{\mathrm{GAS}} C_{\mathrm{CO} \& \mathrm{H}_{2}}+\frac{A_{p} b \wp_{e} C_{\mathrm{CO} \& \mathrm{H}_{2}}}{R_{p}^{2}\left(1 / R_{C}-1 / R_{p}\right)} \\
& \quad+A_{p} b \frac{R_{C}^{2}}{R_{p}^{2}}\left(-X \cdot k_{1\left(\mathrm{CO} \& \mathrm{H}_{2}\right)} C_{\mathrm{Fe}_{2} \mathrm{O}_{3}}+k_{2\left(\mathrm{CO} \& \mathrm{H}_{2}\right)} C_{\mathrm{Fe}_{3} \mathrm{O}_{4}}\right) .
\end{aligned}
$$

(c) $\mathrm{FeO}$ :

$$
\begin{aligned}
-r_{\mathrm{FeO}}= & A_{p} b k_{\mathrm{GAS}} C_{\mathrm{CO} \& \mathrm{H}_{2}}+\frac{A_{p} b \wp_{e} C_{\mathrm{CO} \& \mathrm{H}_{2}}}{R_{p}^{2}\left(1 / R_{C}-1 / R_{p}\right)} \\
& +A_{p} b \frac{R_{C}}{R_{p}^{2}}\left(-Y \cdot k_{2\left(\mathrm{CO} \& \mathrm{H}_{2}\right)} C_{\mathrm{Fe}_{3} \mathrm{O}_{4}}\right. \\
& \left.+k_{3\left(\mathrm{CO} \& \mathrm{H}_{2}\right)} C_{\mathrm{FeO}}\right) .
\end{aligned}
$$

(d) Fe:

$$
\begin{aligned}
-r_{\mathrm{Fe}}= & A_{p} b k_{\mathrm{GAS}} C_{\mathrm{CO} \& \mathrm{H}_{2}}+\frac{A_{p} b \wp_{e} C_{\mathrm{CO} \& \mathrm{H}_{2}}}{R_{p}^{2}\left(1 / R_{C}-1 / R_{p}\right)} \\
& +A_{p} b \frac{R_{C}}{R_{p}^{2}}\left(-Z \cdot k_{3\left(\mathrm{CO} \& \mathrm{H}_{2}\right)} C_{\mathrm{FeO}}\right) .
\end{aligned}
$$

(e) $\mathrm{CO}$ :

$$
\begin{aligned}
& -r_{\mathrm{CO}-\text { reduction }} \\
& =A_{p} b k_{\mathrm{GAS}} C_{\mathrm{CO}}+\frac{A_{p} b \wp_{e} C_{\mathrm{CO}}}{R_{p}^{2}\left(1 / R_{C}-1 / R_{p}\right)} \\
& +A_{p} b \frac{R_{C}^{2}}{R_{p}^{2}} V_{1}\left(k_{1(\mathrm{CO})} C_{\mathrm{Fe}_{2} \mathrm{O}_{3}}+k_{2(\mathrm{CO})} C_{\mathrm{Fe}_{3} \mathrm{O}_{4}}+k_{3(\mathrm{CO})} C_{\mathrm{FeO}}\right) .
\end{aligned}
$$

(f) $\mathrm{H}_{2}$ :

$$
\begin{aligned}
& -r_{\mathrm{H}_{2}-\text { reduction }} \\
& =A_{p} b k_{\mathrm{GAS}} C_{\mathrm{H}_{2}}+\frac{A_{p} b \wp_{e} C_{\mathrm{H}_{2}}}{R_{p}^{2}\left(1 / R_{C}-1 / R_{p}\right)} \\
& \quad+A_{p} b \frac{R_{C}^{2}}{R_{p}^{2}} V_{2}\left(k_{1\left(\mathrm{H}_{2}\right)} C_{\mathrm{Fe}_{2} \mathrm{O}_{3}}+k_{2\left(\mathrm{H}_{2}\right)} C_{\mathrm{Fe}_{3} \mathrm{O}_{4}}+k_{3\left(\mathrm{H}_{2}\right)} C_{\mathrm{FeO}}\right)
\end{aligned}
$$

Here, kinetic equations $r_{i}$ shown in (50)-(55) are formulated based on reaction rate on 1 single pellet. Therefore, they must be multiplied by the number of pellets per unit volume $\left(n_{p}\right)$ to get the overall reaction rate.

Reaction constants $\left(k_{1}, k_{2}\right.$, and $\left.k_{3}\right)$ in (50)-(55) are modeled based on Arrhenius method which is stated as

$$
k_{i}=k_{o} \cdot \exp \left[\frac{-E_{A}^{+}}{R T}\right] .
$$

Here, as for two variables unknown in (56), those are preexponential constant $k_{o}$ and activation energy $E_{A}$. Note that the corresponding values are different for each reduction reaction by $\mathrm{CO}$ and $\mathrm{H}_{2}$. Many literatures focus on the comparison of $E_{A}$ values rather than $k_{o}$, because the variation of $k_{o}$ values is large and highly dependent on research condition. The value of activation energy $\left(E_{A}\right)$ is important to get good result. The $k_{o}$ and $E_{A}$ values used in this research are adopted from Aguilar et al. [5]. The formulations of each $k_{i}$ are shown in Table 1.

Overall kinetic constant on gas film $k_{\mathrm{GAS}}$ is calculated based on formulation proposed by Parisi and Laborde [6] as stated as

$$
k_{\mathrm{GAS}}=0.00225 \exp \left[\frac{-14700}{82.06 T}\right]
$$

while effective diffusion coefficient $\wp_{e}$ is calculated using

$$
\wp_{e}=\frac{\varepsilon_{p} \cdot D}{\tau_{p}} .
$$

Considering the unreacted core model, it is possible to relate the radius of the unreacted core $\left(r_{c}\right)$ with the solid conversion (Co) by

$$
R_{C}=\left(R_{p}^{3}-\frac{\mathrm{Co} \cdot M_{w}}{n_{p} 4 \pi \rho}\right)^{1 / 3}
$$

where

$$
\mathrm{Co}=\left(C_{\mathrm{CO}}^{0}-C_{\mathrm{CO}}\right)+\left(C_{\mathrm{H}_{2}}^{0}-C_{\mathrm{H}_{2}}\right) .
$$

Simulation is carried out on sponge iron production capacity of 2500 tone/day. Reduction gas flow rate required is about $125000 \mathrm{~m}^{3}$ /hour, while leaking cooling gas flow rate from isobaric zone is $4700 \mathrm{~m}^{3}$ /hour.

Calculation of the model is executed by using finite element method. The calculation is divided by many segments along height of reduction zone. Figure 4 shows the simulation algorithm to solve mathematical equation on the cooling zone. Flow numbers shown in this figure refer to Figure 1. By using data at flow 1 and 6, we can then solve the mathematical model simultaneously. To check the validity of the model, we have to compare the result at flow 4 and 5 with data from the plant. If their temperature and concentration of each flow are not in agreement with reference, we have to adjust correction factor $R_{f}$ for temperature and $f_{k}$ for concentration. There are $1 R_{f}$ and $5 f_{k}$ involved in the calculation at reduction zone. Factor $R_{f}$ is differentiated 
TABLE 1: Reaction constants formulation for kinetic equation of iron reduction.

\begin{tabular}{lcc}
\hline & $\mathrm{CO}$ & $\mathrm{H}_{2}$ \\
\hline $\mathrm{Fe}_{2} \mathrm{O}_{3} \rightarrow \mathrm{Fe}_{3} \mathrm{O}_{4}$ & $k_{i(\mathrm{CO})}=9 \cdot \exp [-49884 / R T]$ & $k_{i\left(\mathrm{H}_{2}\right)}=45 \cdot \exp [-49884 / R T]$ \\
$\mathrm{Fe}_{3} \mathrm{O}_{4} \rightarrow \mathrm{FeO}$ & $k_{i(\mathrm{CO})}=0.072 \cdot \exp [-21616 / R T]$ & $k_{i\left(\mathrm{H}_{2}\right)}=0.36 \cdot \exp [-21616 / R T]$ \\
$\mathrm{FeO} \rightarrow \mathrm{Fe}$ & $k_{i(\mathrm{CO})}=0.036 \cdot \exp [-21616 / R T]$ & $k_{i\left(\mathrm{H}_{2}\right)}=9 \cdot \exp [-21616 / R T]$ \\
\hline
\end{tabular}

TABLE 2: Correction factor value used in mathematical model of reduction zone.

\begin{tabular}{llcc}
\hline No. & Note & $\begin{array}{c}\text { Methane } \\
\text { reforming }\end{array}$ & $\begin{array}{c}\text { Water gas shift } \\
\text { reaction }\end{array}$ \\
\hline$(1)$ & Correction factor $f$ & - & 0.036 \\
\hline$(2)$ & Reaction constant rate & $* 0.00199$ & - \\
\hline$(3)$ & $R_{f}$ & 0.02 \\
\hline & $X$ & 0.02 \\
& $Y$ & 40 \\
$(4)$ & $Z$ & 14800 \\
& $V_{1}$ & $4.6 E-6$ \\
& $V_{2}$ & \multicolumn{2}{c}{$5.1 E-6$} \\
\hline$*$
\end{tabular}

${ }^{*}$ Reaction constant rate $\left(\mathrm{mol} / \mathrm{m}^{2} \cdot \mathrm{s} \cdot \mathrm{Pa}^{0.94}\right)$.

based on the temperature phase, while $f_{k}$ is differentiated based on kinetic equation of each reaction.

Reaction constant rate value for methane reforming is not explained in literature. The value shown in Table 2 is obtained from the calculation after fitting with the reference data.

\section{Results and Discussion}

3.1. Temperature, Gas, and Solid Profile along Reduction Zone. Table 3 resumes the comparison between reference data and simulation. Reference data are taken from Project Final Report [18]. From this table, one observes that simulation precisely predicts reference data but not calculation result on the other zone. Here, root mean square error (RMSE) shows a value around 0.19 . Gas composition data for flow number 1 are not available in the plant, but they can be calculated from mass balance resulted from mixing between reduction gas inlet (flow number 2) and leaking cooling gas (flow number 3). Leaking cooling gas is obtained from Alamsari et al. [19].

Reduced iron data (flow number 6) at the outlet of reduction zone are also unavailable in the plant. However, the simulation results from the calculation of reduction zone already are in good agreement with simulation result produced from the calculation in isobaric zone [19]. Alamsari et al. propose model for isobaric and cooling zone of the same reactor. They found that metallization degree of the product reduces around $1.72 \%$ after leaving isobaric and cooling zone. As metallization degree of sponge iron product from the plant data is stated about $92.49 \%$, it implies that the product (reduced iron) before entering isobaric and cooling zone has metallization degree of $94.21 \%$. This value agrees with simulation result produced from this research. Reduced iron shown in Table 3 produces metallization degree around
TABLE 3: Comparison between reference data and simulation.

\begin{tabular}{|c|c|c|c|c|}
\hline Flow & Note & Plant data & $\begin{array}{l}\text { Simulation } \\
\text { Reduction } \\
\text { zone }\end{array}$ & $\begin{array}{l}\text { results } \\
\text { Isobaric } \\
\text { zone }\end{array}$ \\
\hline \multirow{8}{*}{ (1) } & $\begin{array}{l}\text { Reduction gas in the bot- } \\
\text { tom of reduction zone }\end{array}$ & & & \\
\hline & Temperature (K) & 1193 & 1193 & \\
\hline & $\mathrm{CH}_{4}$ (\% vol.) & & 2.9 & \\
\hline & $\mathrm{H}_{2}$ (\% vol.) & & 42.1 & \\
\hline & CO (\% vol.) & & 9.58 & \\
\hline & $\mathrm{CO}_{2}$ (\% vol.) & & 2.26 & \\
\hline & $\mathrm{N}_{2}$ (\% vol.) & & 3.72 & \\
\hline & $\mathrm{H}_{2} \mathrm{O}$ (\% vol.) & & 1.36 & \\
\hline \multirow{8}{*}{ (2) } & Reduction gas inlet & & & \\
\hline & Temperature (K) & 1203 & & \\
\hline & $\mathrm{CH}_{4}$ (\% vol.) & 3.7 & & \\
\hline & $\mathrm{H}_{2}$ (\% vol.) & 71.86 & & \\
\hline & CO (\% vol.) & 16.5 & & \\
\hline & $\mathrm{CO}_{2}$ (\% vol.) & 3.8 & & \\
\hline & $\mathrm{N}_{2}$ (\% vol.) & 1.8 & & \\
\hline & $\mathrm{H}_{2} \mathrm{O}$ (\% vol.) & 2.34 & & \\
\hline \multirow{8}{*}{ (3) } & $\begin{array}{l}\text { Leaking gas from isobaric } \\
\text { zone }\end{array}$ & & & \\
\hline & Temperature (K) & & & 1139 \\
\hline & $\mathrm{CH}_{4}$ (\% vol.) & & & 50.13 \\
\hline & $\mathrm{H}_{2}$ (\% vol.) & & & 45.63 \\
\hline & CO (\% vol.) & & & 0.983 \\
\hline & $\mathrm{CO}_{2}$ (\% vol.) & & & 3.03 \\
\hline & $\mathrm{N}_{2}$ (\% vol.) & & & 1.14 \\
\hline & $\mathrm{H}_{2} \mathrm{O}$ (\% vol.) & & & 0.12 \\
\hline \multirow{8}{*}{ (4) } & Reduction gas wastes & & & \\
\hline & Temperature (K) & 657.5 & 657.5 & \\
\hline & $\mathrm{CO}_{2}(\%$ vol. $)$ & 9.0 & 8.5 & \\
\hline & $\mathrm{CH}_{4}$ (\% vol.) & 4.4 & 4.5 & \\
\hline & CO (\% vol.) & 12.1 & 11.7 & \\
\hline & $\mathrm{H}_{2} \mathrm{O}$ (\% vol.) & 23.4 & 23.9 & \\
\hline & $\mathrm{N}_{2}$ (\% vol.) & 12 & 1.7 & \\
\hline & $\mathrm{H}_{2}$ (\% vol.) & 49.7 & 49.5 & \\
\hline
\end{tabular}

94.22\%. Alamsari et al. [19] also show solid temperature profile along isobaric and cooling zone. Reduced iron temperature was obtained about $1169 \mathrm{~K}$. This value is close with simulation result shown in Table 3. 


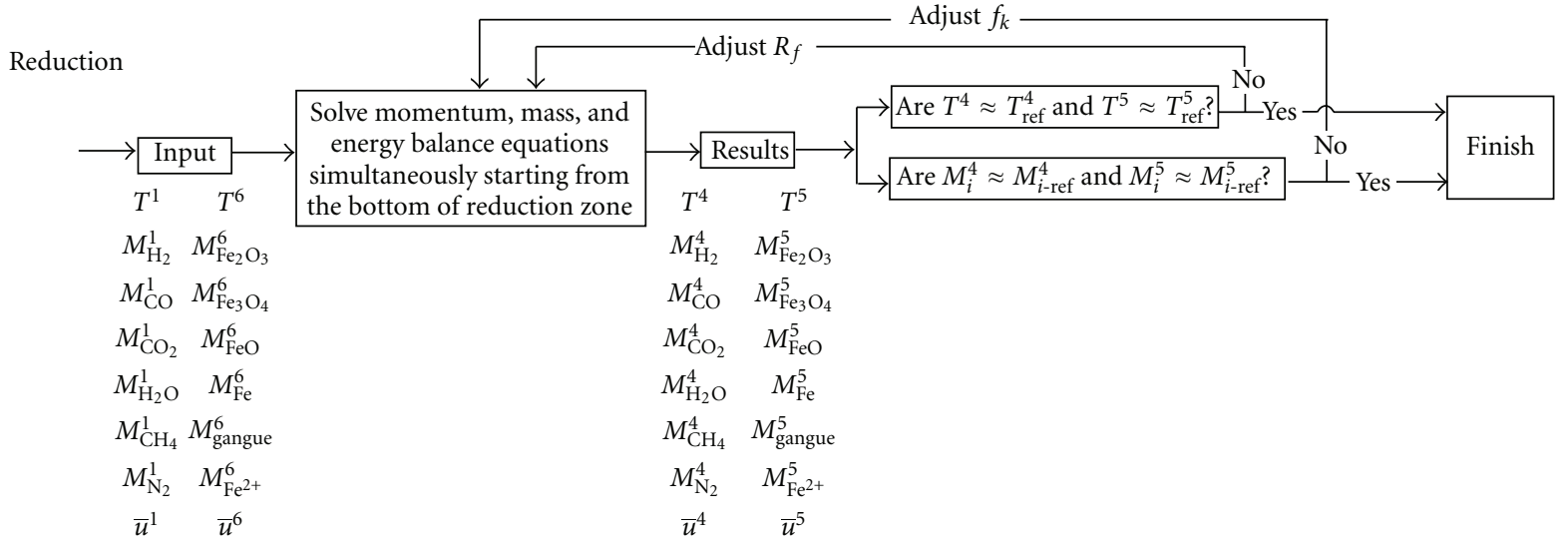

FIGURE 4: Simulation algorithm on the reduction zone.

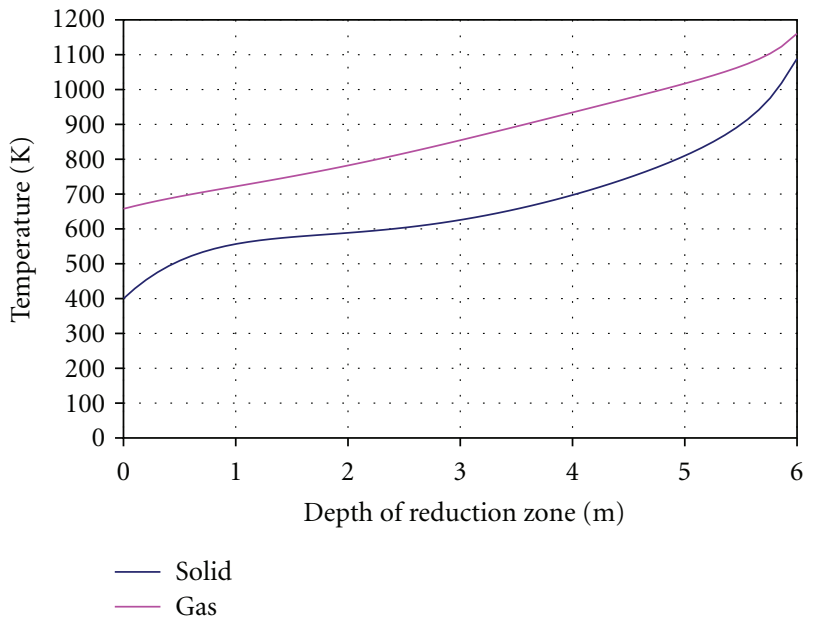

(a)

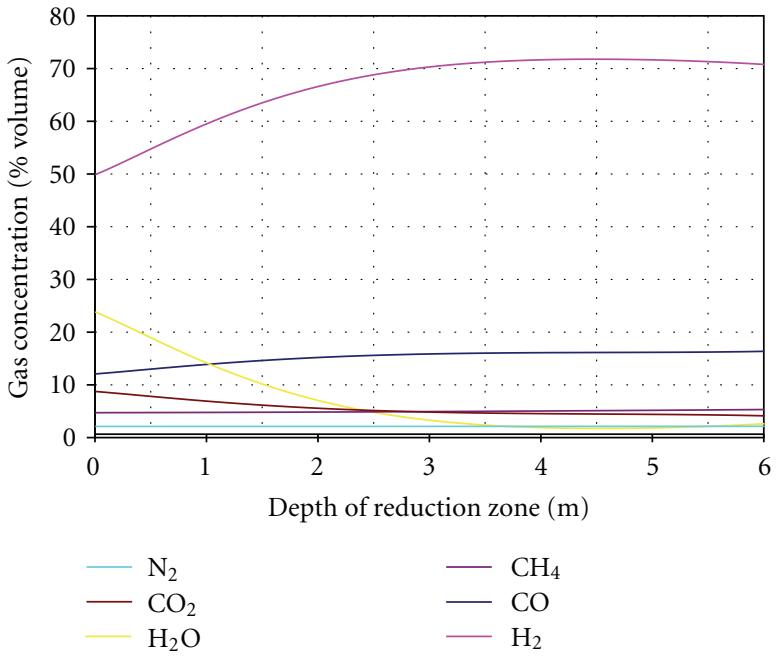

(b)

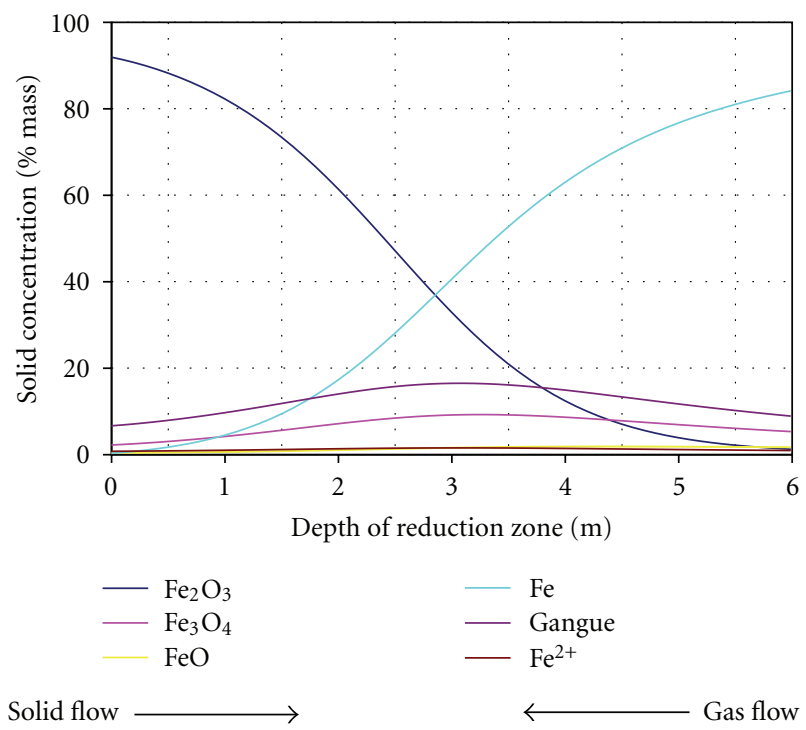

(c)

Figure 5: Profiles of many variables as a function of the depth of reduction zone; (a) gas and solid temperature; (b) gas concentration; (c) solid concentration. 

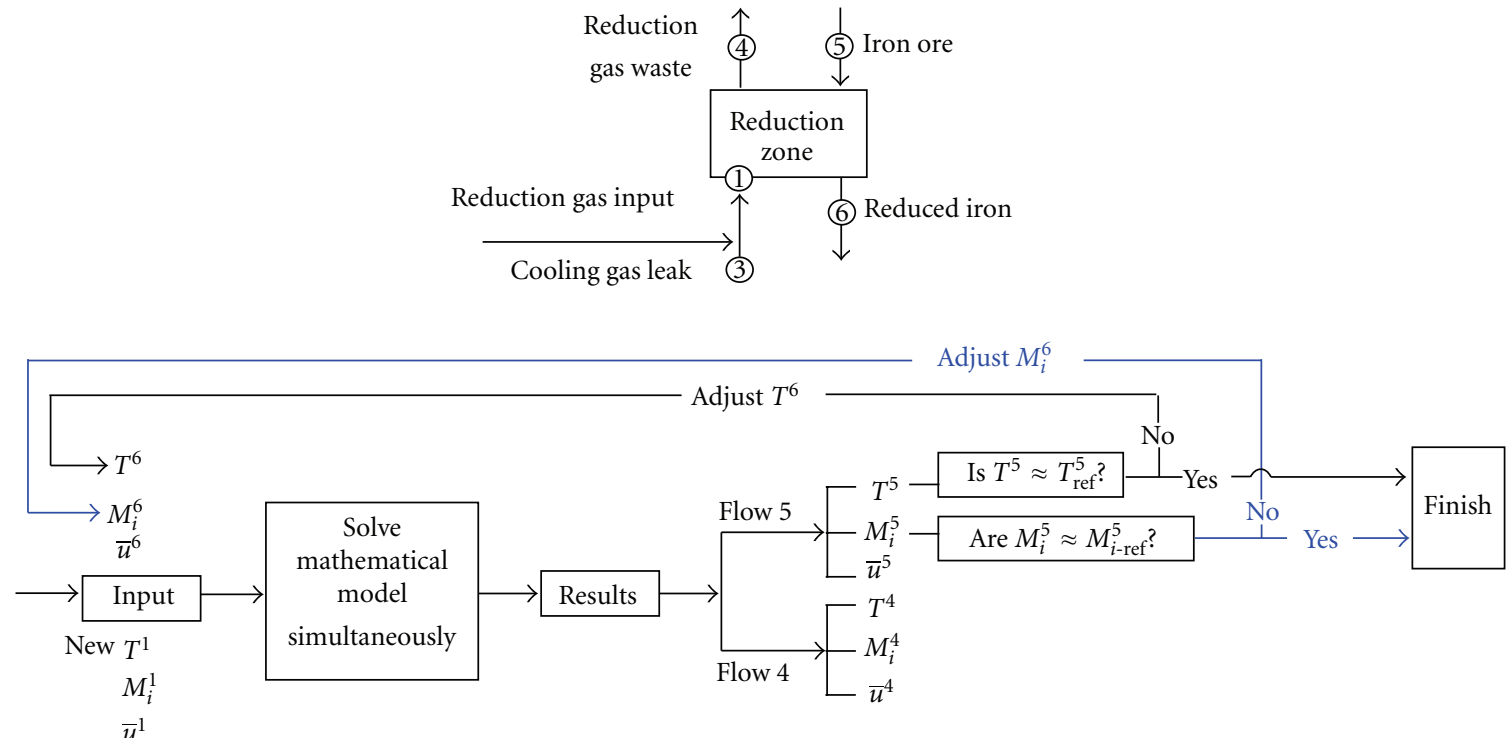

FIGURE 6: Simulation algorithm of reduction gas temperature effect on metallization degree of reduced iron.

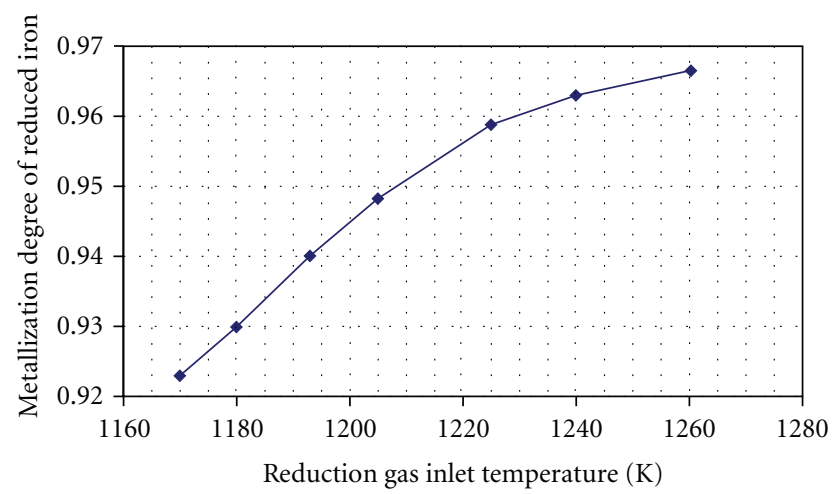

Figure 7: Metallization degree as function of gas inlet temperature.

The composition data of iron oxides are only provided for hematite $\left(\mathrm{Fe}_{2} \mathrm{O}_{3}\right)$ as the main component, while the other components such as magnetite $\left(\mathrm{Fe}_{3} \mathrm{O}_{4}\right)$ and wustite $(\mathrm{FeO})$ are ignored because they have very small composition compared with hematite. However, since the main goal in this research is to model the whole iron reactor and kinetics equation is only small part of the model, the concentration of magnetite $\left(\mathrm{Fe}_{3} \mathrm{O}_{4}\right)$ and wustite $(\mathrm{FeO})$ will not affect the result.

Figure 5(a) illustrates temperature profiles along reduction zone for gas and solid phases. Inlet and outlet temperatures are in good agreement with the reference data. One observes that temperature profiles along reduction zone are increased with an increase in gas and solid temperature from the direction of solid flow. The corresponding concentration profiles for gas phase are shown in Figure 5(b). Except nitrogen, other components show composition changes which are caused by reactions in the gas phase. Gas mole balance reactions for methane reforming, iron reduction, and water gas shift reaction already have an agreement. Figure 5(c) depicts solid concentration profile along reduction zone. It is observed that, at the beginning of reduction zone inlet, total $\mathrm{Fe}$ in the ore is dominated by $\mathrm{Fe}_{2} \mathrm{O}_{3}$, while as reactions occur, $\mathrm{Fe}_{2} \mathrm{O}_{3}$ is slowly reduced by reduction gas to release oxygen.

3.2. Analysis the Effect of Temperature and Composition of Reduction Gas on Product Quality. Reduction gas as reactant in reduction reaction plays an important role in an enhancement of product quality. The optimum condition of reduction gas must be investigated to get the high quality. The effect of reduction gas on product quality is investigated by studying the effects of temperature and composition of reduction gas on metallization degree. The investigation is carried out by numerical simulation using the mathematical model arranged before.

3.3. Temperature. An effect of temperature on metallization degree is numerically investigated by varying inlet temperature of reduction gas on the range of $1170-1260 \mathrm{~K}$ with an increment around $10 \mathrm{~K}$. The calculation results on reduction zone (Table 3 ) are used as the basis values of this simulation. The inlet temperature in this simulation is referred to as the temperature mixing of leaking cooling gas at flow 3 and reduction gas at flow 2 (see Figure 1).

Figure 6 shows the algorithm of reduction gas temperature effect on metallization degree. The calculation is started from the bottom of reduction zone. Data at flow 1 and 6 are used as input in the calculation. The simulation is carried out for each value of gas inlet temperature, and new data at flow 4 and 5 of each value are obtained. The result at flow 5 must be in good agreement with the plant data since this flow is the real input in iron reactor which is replaced by flow 6 . Therefore, we have to adjust temperature $(T)$ and concentration $(M)$ at flow 6 until temperature $(T)$ and concentration $(M)$ at flow 5 agree with reference data.

Figure 7 illustrates the relation between metallization degree of reduced iron with reduction gas inlet temperature. It is observed that reduction reaction of hematite produces 

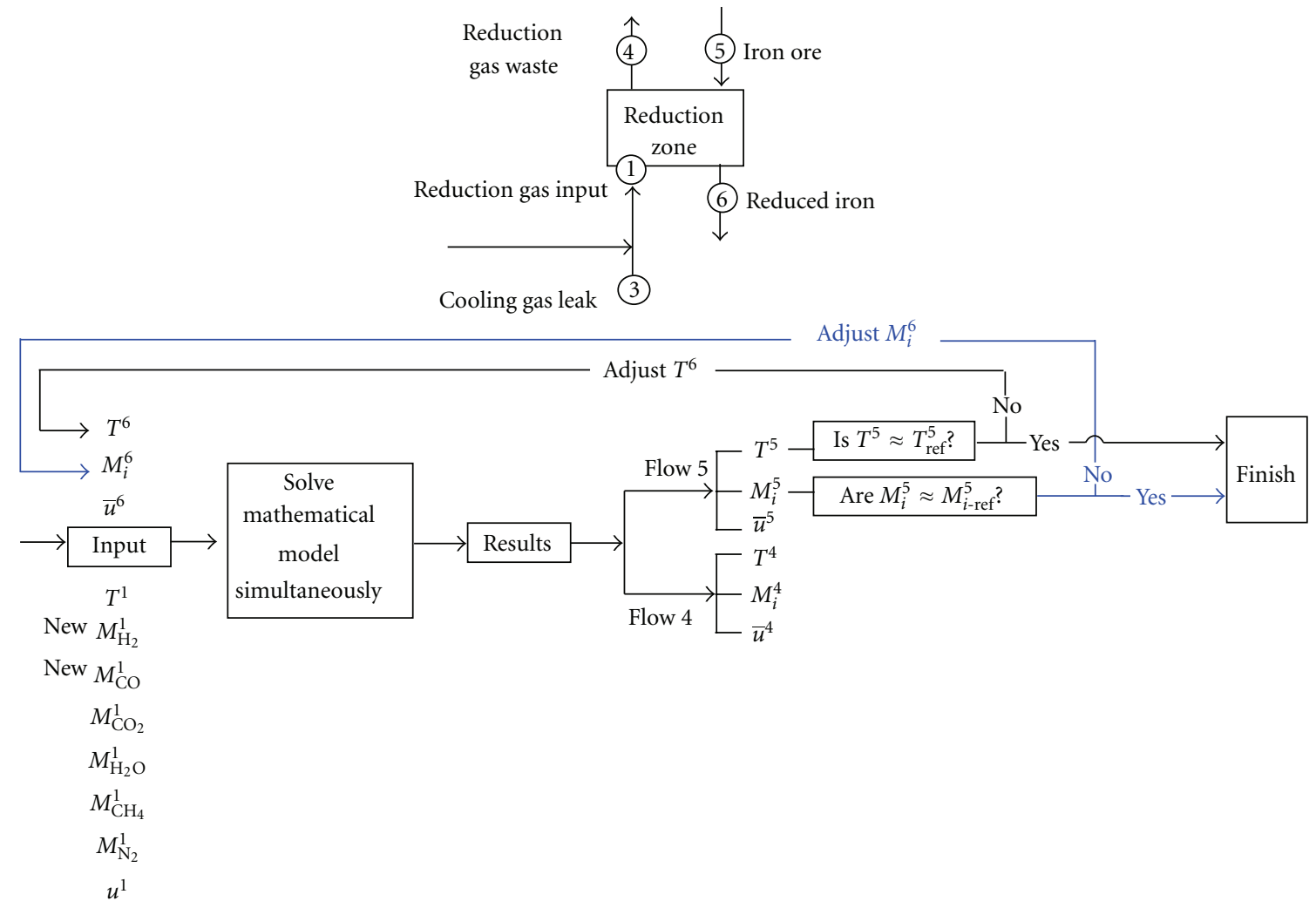

FIGURE 8: Simulation algorithm of reduction gas composition effect on metallization degree of reduced iron.

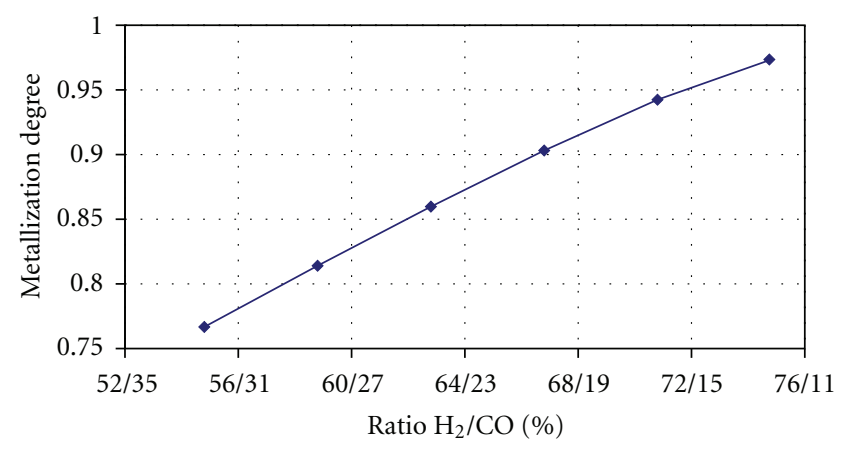

FIgURE 9: Metallization degree as function of ratio $\mathrm{H}_{2}-\mathrm{CO}$.

higher metallization degree as an increase in reduction gas inlet temperature. This occurs because the increase in reduction gas inlet temperature causes both an enhancement of reaction temperature and an accelerate reaction flow rate. Zhang and Ostrovski [1] obtain the same result when they investigated iron ore reduction by $\mathrm{H}_{2}-\mathrm{CH}_{4}-\mathrm{Ar}$ gas mixtures. They disclose that the rate of iron ore reduction is intensified with an increase in temperature.

Although an increase in temperature can be an alternative way to get a better metallization degree, this increasing is limited by physical properties of iron. Diaz et al. [20] suggest a setting gas inlet temperature high enough to allow for liquid-phase migration of the metal iron within the pellets. However, temperature must be also maintained below the point at which the pellets became sticky. Sticky irons bring troubles because they will stimulate an agglomeration, sintered to each other and form accretions on the furnace/reactor walls. Based on the plant data, ring reduction temperature over $1153 \mathrm{~K}$ will initiate formation of sticky iron. It implies that reduction gas inlet temperature should be below $1246 \mathrm{~K}$ to avoid this problem.

3.4. Composition. In general, hydrogen and carbon monoxide are good reducers for iron ore. The change in their composition in reduction gas will affect quality of the product. Simulation of the effect of composition changes on metallization degree is performed on various composition of $\mathrm{H}_{2}$ and CO. Composition of other gas is maintained on the same ratio.

Figure 8 shows the simulation algorithm of reduction gas composition effect on metallization degree. Note that correction factor and other values resulted from the calculation in reduction zone are used as the basis of calculation. By using data at flow 1 and 6 as calculation input, we can solve the model and get the new value for each data at flow 4 and 5 .

Figure 9 depicts metallization degree as a function of ratio $\mathrm{H}_{2}-\mathrm{CO}$. One observes that an increase in $\mathrm{H}_{2}$ composition while an attenuation of $\mathrm{CO}$ will produce higher metallization degree. This implies that $\mathrm{H}_{2}$ is better reducer than CO. The same conclusion is reported by Bonalde et al. [2], El-Geassy and Rajakumar [3], and Pineau et al. [4]. Bonalde et al. [2] analyze metallization degree produced by using $100 \% \mathrm{H}_{2}, 100 \%$ carbon monoxide, and midrex gas $\left(55 \% \mathrm{H}_{2}-34 \% \mathrm{CO}\right)$ as reducer, respectively. They reported 
that the fastest reaction occurs when $\mathrm{H}_{2}$ is used and the slowest rate is observed when CO is used, while midrex gas is intermediate. When El-Geassy and Rajakumar [3] modeled the reduction of iron starting from wustite, they came out with the same conclusion. Pineau et al. [4] dealt with the reduction of $\mathrm{Fe}_{2} \mathrm{O}_{3}$ in the temperature range of $220-680^{\circ} \mathrm{C}$. They found that the rate of reduction of iron oxide with $\mathrm{H}_{2}$ is systematically higher than that obtained by CO.

\section{Conclusions}

Reduction zone of iron reactor has been simulated. Kinetics equation of reduction of hematite to iron metal, methane reforming, and water gas shift reaction are taken into account in the model. Simulation results are in good agreement with the reference data.

Temperature profiles along reduction zone show an increase in gas and solid temperature from the direction of solid flow. Gas concentration profiles show composition changes which are caused by reactions in the gas phase. Gas mole balance reaction for methane reforming, reduction, and water gas shift reaction already have an agreement.

At the beginning of reduction zone inlet, solid concentration profile shows that total $\mathrm{Fe}$ in the ore is dominated by $\mathrm{Fe}_{2} \mathrm{O}_{3}$. As reactions occur, $\mathrm{Fe}_{2} \mathrm{O}_{3}$ is slowly reduced by reduction gas to release oxygen. Reduced iron from reduction zone produces metallization degree until 94.22\%.

When an attenuation of $\mathrm{CO}$ yields, an increase in $\mathrm{H}_{2}$ composition produces higher metallization degree. Metallization degree is also increased with an increase in gas inlet temperature. Reduction gas temperature over $1246 \mathrm{~K}$ is not recommended because the formation of sticky iron will be initiated.

\section{Nomenclature}

$A_{s p}: \quad$ Pellets surface area per unit reactor volume, $\mathrm{m}^{2} / \mathrm{m}^{3}$

$b: \quad$ Stoichiometric coefficients

C: $\quad$ Concentration, mole $/ \mathrm{m}^{3}$

$C p: \quad$ Heat capacity, $\mathrm{J} / \mathrm{moleK}$

$D: \quad$ Molecular diffusivity of oxygen in gas

$D_{n}$ : $\quad$ Effective diffusivity of oxygen

$\varepsilon_{p}: \quad$ Pellets porosity

$E_{A}$ : $\quad$ Activation energy, J/mole

$f$ : $\quad$ Correction factor

M: $\quad$ Molar flow rate, mole $/ \mathrm{sec} \cdot \mathrm{m}^{2}$

$M_{w}$ : $\quad$ Molecular weight, $\mathrm{kg} /$ mole

$n_{\text {pellet}}$ : Number of pellets per unit volume $\left(1 / \mathrm{m}^{3}\right)$

$h$ : Convection heat transfer coefficient, $\mathrm{J} / \mathrm{s} \cdot \mathrm{m}^{2} \cdot \mathrm{K}$

$H_{R(298 \mathrm{~K})}$ : Standard reaction enthalpy, J/mole

$k$ : $\quad$ Preexponential constant mole $\mathrm{C} / \mathrm{sec} \cdot \mathrm{m}^{3} \cdot \mathrm{Pa}$

$L: \quad$ Length of reactor cooling zone, $\mathrm{m}$

p: $\quad$ Pressure, $\mathrm{Pa}$

Q: $\quad$ Flux of material, mole $/ \mathrm{cm}^{2} \cdot \mathrm{sec}$

$r$ : $\quad$ Reaction rate, $\mathrm{mole} / \mathrm{m}^{3} \cdot \mathrm{sec}$
$R: \quad$ Gas constant, $\mathrm{Pa} \cdot \mathrm{m}^{3} / \mathrm{mole} \cdot \mathrm{K}$

$R_{c}$ : $\quad$ Radius of unreacted core, $\mathrm{m}$

$R_{p}: \quad$ Pellets radius, $\mathrm{m}$

$R_{f}: \quad$ Relaxation factor

T: $\quad$ Temperature, $\mathrm{K}$

$\tau_{p}: \quad$ Pore structure tortuosity

$\bar{u}: \quad$ Superficial velocity, $\mathrm{m} / \mathrm{s}$

$V: \quad$ Coefficients depending on weight

relationships and equilibrium conditions

$X, Y, Z$ : Weight coefficients

$z$ : $\quad$ Space variable inside reactor, $m$

solid: Solid

$R: \quad$ Reaction.

\section{Superscripts}

+: Forward reaction

-: Backward reaction.

\section{Subscripts}

1: Reduction reaction by $\mathrm{H}_{2}$

2: Reduction reaction by $\mathrm{CO}$

3: Methane reforming reaction

4: Water gas shift reaction

$i$ : $i$ th reaction.

\section{References}

[1] J. Zhang and O. Ostrovski, "Iron ore reduction/cementation: experimental results and kinetic modelling," Ironmaking and Steelmaking, vol. 29, no. 1, pp. 15-21, 2002.

[2] A. Bonalde, A. Henriquez, and M. Manrique, "Kinetic analysis of the iron oxide reduction using hydrogen-carbon monoxide mixtures as reducing agent," ISIJ International, vol. 45, no. 9, pp. 1255-1260, 2005.

[3] A. A. El-Geassy and V. Rajakumar, "Gaseous Reduction of Wustite with $\mathrm{H}_{2}, \mathrm{CO}$ and $\mathrm{H}_{2}-\mathrm{CO}$ mixtures," Transactions of the Iron and Steel Institute of Japan, vol. 25, pp. 449-458, 1985.

[4] A. Pineau, N. Kanari, and I. Gaballah, "Kinetics of reduction of iron oxides by $\mathrm{H}_{2}$. Part I: low temperature reduction of hematite," Thermochimica Acta, vol. 447, no. 1, pp. 89-100, 2006.

[5] J. Aguilar, R. Fuentes, and R. Viramontes, "Simulation of iron ore reduction in a fixed bed," Modelling and Simulation in Materials Science and Engineering, vol. 3, no. 2, pp. 131-147, 1995.

[6] D. R. Parisi and M. A. Laborde, "Modeling of counter current moving bed gas-solid reactor used in direct reduction of iron ore," Chemical Engineering Journal, vol. 104, no. 1-3, pp. 3543, 2004.

[7] Y. Takenaka, Y. Kimura, K. Narita, and D. Kaneko, "Mathematical model of direct reduction shaft furnace and its application to actual operations of a model plant," Computers and Chemical Engineering, vol. 10, no. 1, pp. 67-75, 1986.

[8] N. S. Srinivasan, "Reduction of iron oxides by carbon in a circulating fluidized bed reactor," Powder Technology, vol. 124, no. 1-2, pp. 28-39, 2002.

[9] O. Levenspiel, Chemical Reaction Engineering, John Wiley \& Sons, New York, NY, USA, 2nd edition, 1962. 
[10] K. Mondal, H. Lorethova, E. Hippo, T. Wiltowski, and S. B. Lalvani, "Reduction of iron oxide in carbon monoxide atmosphere-reaction controlled kinetics," Fuel Processing Technology, vol. 86, no. 1, pp. 33-47, 2004.

[11] Y. Iguchi and S. Yokomoto, "Kinetics of the reactions in carbon composite iron ore pellets under various pressures from vacuum to $0.1 \mathrm{MPa}$, ISIJ International, vol. 44, no. 12, pp. 20082017, 2004.

[12] G. V. Reklaitis, Introduction to Material and Energy Balances, John Wiley \& Sons, 1st edition, 1983.

[13] D. W. Green and R. H. Perry, Perry's Chemical Engineer's Handbook, The McGraw-Hill Companies, 7th edition, 1999.

[14] C. C. Furnas, "Heat transfer from a gas stream to a bed of broken solids," Industrial and Engineering Chemistry, vol. 22, no. 1, pp. 26-31, 1930.

[15] P. Munster and H. J. Grabke, "Kinetics of the steam reforming of methane with iron, nickel, and iron-nickel alloys as catalysts," Journal of Catalysis, vol. 72, no. 2, pp. 279-287, 1981.

[16] F. Bustamante, R. M. Enick, A. V. Cugini et al., "High-temperature kinetics of the homogeneous reverse water-gas shift reaction," AIChE Journal, vol. 50, no. 5, pp. 1028-1041, 2004.

[17] J. Shi, E. Donskoi, D. L. S. McElwain, and L. J. Wibberley, "Modelling the reduction of an iron ore-coal composite pellet with conduction and convection in an axisymmetric temperature field," Mathematical and Computer Modelling, vol. 42, no. 1-2, pp. 45-60, 2005.

[18] Empowerment and Research Society Institution of Bandung Institute of Technology (LPPM ITB), "Final report of direct reduction process simulation on Krakatau Steel Plant for preimplementation of zero reformer process," p. 55, June 2005.

[19] B. Alamsari, S. Torii, A. Trianto, and Y. Bindar, "Numerical simulation of iron ore reactor isobaric and cooling zone to investigate total carbon formation in sponge iron," in Proceedings of the International Conference of Modeling and Simulation, pp. 88-92, Tokyo, Japan, May 2009.

[20] C. M. Diaz, A. Vahed, D. Shi, C. D. Doyle, A. E. M. Warner, and D. J. MacVicar, "Low temperature thermal upgrading of lateritic ores," U S patent no. 5178666, 1993. 

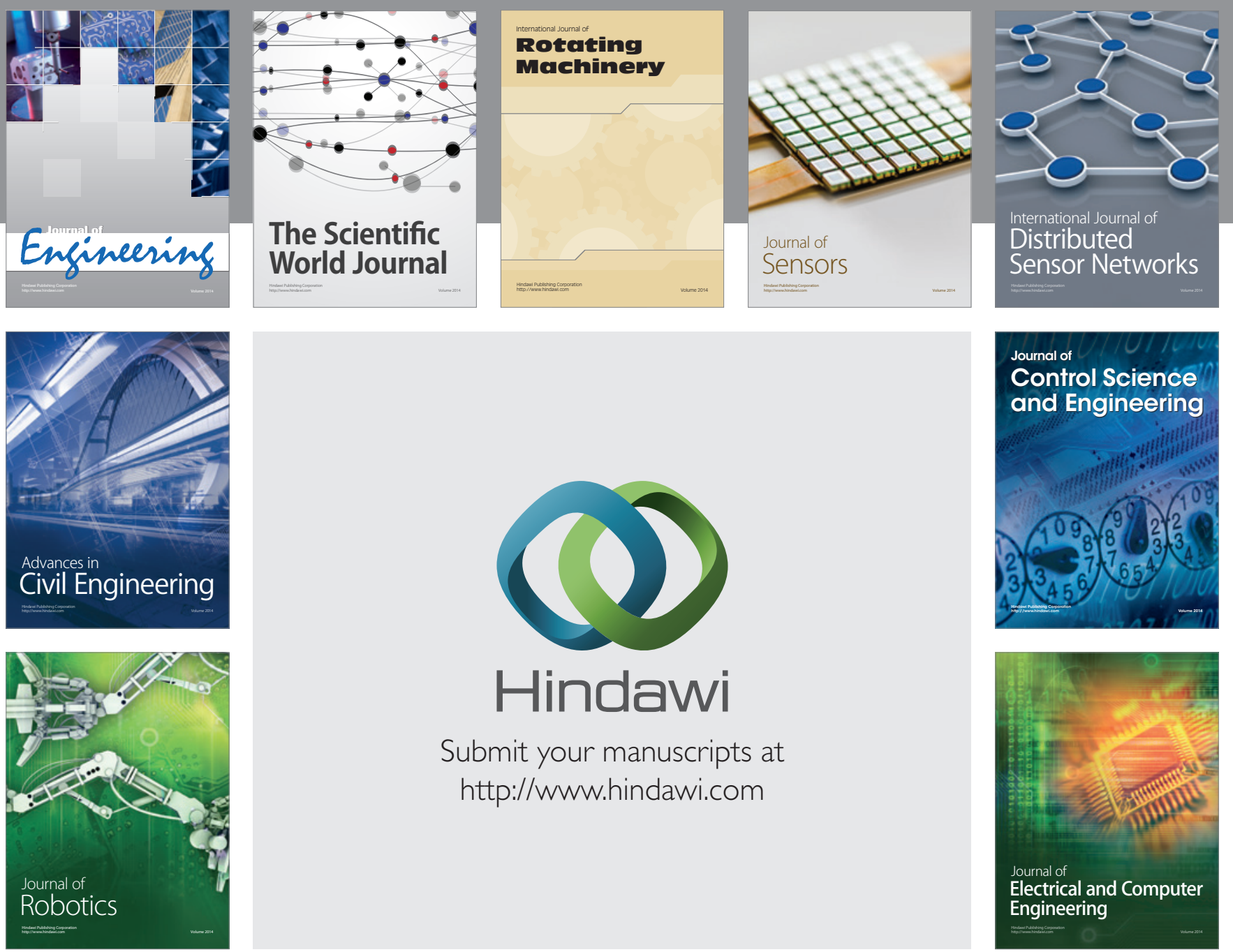

Submit your manuscripts at

http://www.hindawi.com
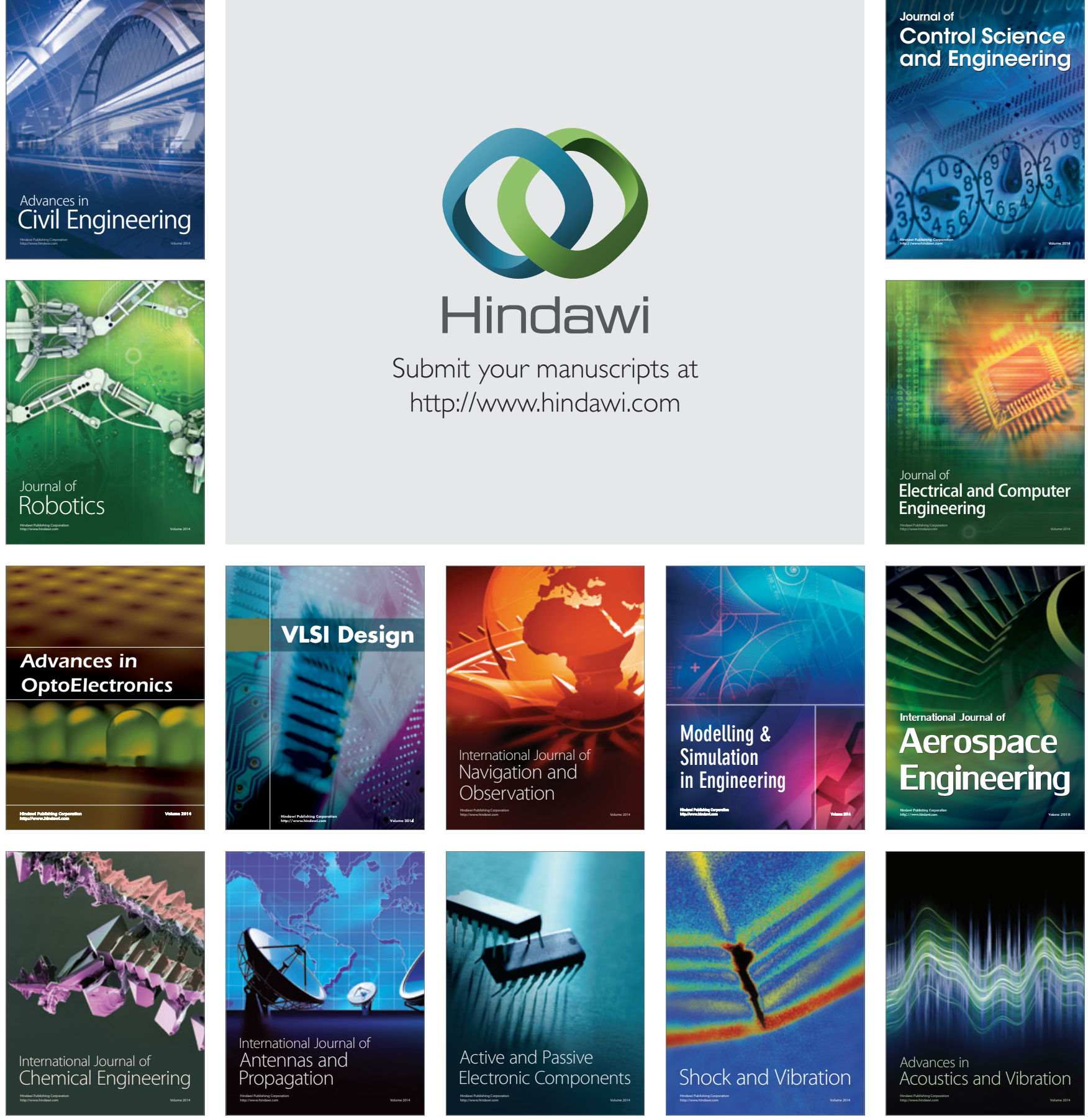